\title{
The Disability Adjusted Lifeyear Losses of Disasters, the Case of Wenchuan Earthquake
}

\author{
Cong Lang, Xinyan Wu*, Mengtan Gao, Guochun Wu \\ Institute of Geophysics, China Earthquake Administration, Beijing 100081, China \\ 地震灾害的生命年损失影响分析一以汶川地震 \\ 为例 \\ 郎从, 吴新燕*, 高孟潭, 伍国春 \\ 中国地震局地球物理研究所, 北京 100081 , 中国
}

\begin{abstract}
This paper uses DALYs to aggregate measure the number of fatalities, of people affected, and the financial damage of disaster impact and apply it to Wenchuan Earthquake. The estimated total number of lifeyear losses is $18,359,222$ years. Injuries and affected people contribute $40.8 \%$ to the total losses, more than fatalities $(25.1 \%)$ or direct damage $(34.1 \%)$. The results reveal following findings. (1) Inconspicuous losses is the most severe disaster losses. Injuries and affected people caused the most losses. (2) Long-term impacts of earthquakes are more serious than shortterm impacts. Therefore, the inconspicuous impacts should be considered more in mitigation policy. Post-disaster recovery and assistance should be long enough.
\end{abstract}

Keywords: Disability Adjusted Life Years; earthquake; disaster impact; Wenchuan earthquake

\section{摘要}

本文使用生命年方法将常用的灾害损 失指标死亡人口、受影响人口和经济损失

*通讯作者：wuxy1977@sina. com. 项目资助: 中国地震局地球物理研究所基本科研业务 费专项资助（编号：DQJB17C10）
换算为生命年损失, 计算汶川地震的灾害 影响。计算结果表明, 汶川地震共造成 $18,359,222$ 年的生命年损失。其中, 受影 响人口导致的生命年损失最大 ( $40.8 \%)$, 大于死亡 (或失踪) 人口 (25.1\%) 和经济 损失 (34.1\%) 带来的生命年损失。这意味 着, 隐形的损失是灾害损失最严重的部 分; 地震长期影响比短期影响更严重。因 此, 在政策制定和援助时应考虑隐形的灾 害影响, 灾后应进行长期恢复和援助, 并 确保政策具有足够时间长度。

关键词: 生命年; 地震灾害; 灾害影响; 汶川地震

\section{1. 引言}

中国的地震区域分布广阔而分散, 地 震事件频繁而强烈 [1] [2]。作为世界人口 第一大国, 经济第二大国, 中国是地震灾 害最为严重的国家之一 [3]。作为集中型灾 害, 地震事件常会带来集中的人员伤亡和 经济损失 [4]。对于地震灾害程度的度量通 常是死亡 (或失踪) 人口、受影响人口和 直接经济损失三个指标。这种三指标的表 述在实际应用上便捷可靠, 但也具有不 足。首先, 由于多指标化, 不同事件造成 的损失往往难以比较。其次, 不同类型的 灾害造成的损失由于其灾害影响特点不 同, 更是难以比较。尤其难以与广布型灾 害进行比较, 容易导致对广布型灾害影响 
的忽视。根据《减轻灾害风险全球评估报 告》的计算, 虽然低发高损的集中型灾害 更加引人注目，但是高发低损的广布型灾 害引发的经济损失却更大, 约占灾害损失 总额的 $45 \%[5]$ 。第三, 死亡人口、经济损 失、受影响人口三个指标之间无法进行比 较, 无法比较哪个指标受灾害影响更严 重。由于传统上对于人口死亡的关注, 另 外两个指标的损失容易被忽视。第四, 灾 害是对人类福祉的阻碍, 是对人类福祉的 倒退 [5]。因此应从人类发展的角度认识理 解灾害。但用死亡人口、受影响人口和经 济损失表述的灾害影响统计无法表达灾害 对于社会经济发展和社会进步的影响。因 此需要科学合理的归一化指标度量灾害影 响。

已有归一化的灾害损失程度度量研究 主要有三个类型：（1）宏观损失程度等 级。此类方法直接使用灾损指标对灾害严 重程度进行分等定级。马宗晋等 (1988) 首先提出统一的灾害损失度量指标, 根据 死亡人口和经济损失的等级定义“灾 度” [6], 并于 1994 年细化和调整了灾度 指标, 将灾害等级划分为一至四级 (特 大、大、中、小） [7]。于庆东（1993）随 后改进了灾度的判别方法 [8]。李祚泳等 （1994）[9］、代博洋等（2009）[10］使用 物元理论对灾害等级划分进行了改进。此 类方法简易方便, 但结论较为宏观和粗 略, 且多采用双指标, 不同灾种、不同灾 害事件仍然难以比较。

(2) 计算灾害损失指标得到标准化的 灾害损失程度变量, 并据此对灾害影响程 度分等定级。冯利华 (1993) 将死亡人 数、受伤人数和直接经济损失的数量折算 为规范化指数 [11], 赵阿兴等 (1993) 计 算灾害损失占社会经济指标的百分比 [12], 冯志泽等 (1994) 使用死亡人口、 重伤人数和经济损失计算灾害指数 [13], 杨仕升 (1996) 借用转换函数使用灰色关 联法计算灾损程度 [14]。随后, 随着数量 统计方法的发展, 标准化指数的确定也逐 渐包含更多的数理统计技术, 任鲁川 （1996）使用模糊综合评判法 [15], 王莺
等 (2013) 使用 $Z$ 指数正态分布曲线的理 论分布区间 [16], 张星 (2009) 使用权摘 法 [17], 张鹏等 (2015) 使用灾损指数几 何平均加和法 [18], 汤家法等 (2015) 使 用主成分分析法 [19] 都进行了标准化指数 的计算和研究。高庆华 (1991)、王劲峰 (1993) 等、魏庆朝等 (1996)、程立海 等（2011）、袁艺（2011）、廖永丰等 （2013）也进行过相关研究 [20]-[25]。但 此类研究得到的灾害损失程度不是一个有 真实物理意义的量, 是人为定义的变量, 只能作为损失严重性的指标, 难以用于后 续研究工作。

(3) 价值化的灾害损失程度度量。此 类方法将灾害造成的损失折算为经济损 失。杜兴信等于 1992 年评价陕西省自然灾 害损失年景时将农田成灾、人口死亡和房 屋倒塌造成的损失全部折算为经济损失, 使用换算得到的经济损失作为损失程度的 度量 [26]。陈秀万 (1996) 在对洪水灾害 损失定量化计算时同样将损失折算为经济 损失 [27]。此种方法得到可以比较的灾害 程度指标, 也使用了具有实际物理意义的 经济损失指征灾害影响程度, 但价值化的 灾害损失度量仍然存在不等价的问题, 因 为同样的货币价值在不同地区存在不等价 性。相较高收入地区, 低收入地区的经济 资源和资本更为分散, 他们获得同样的货 币资源更为困难，因此即使是同样货币价 值的灾害损失, 低收入地区也会造成更为 严重的后果 [28]。另外, 此方法还存在时 间价值不同, 不同币种受汇率波动影响的 缺点。并且, 经济损失的灾害影响表达虽 然可以体现灾害对于经济发展的影响, 但 无法体现其对社会进步和人类福祉的影 响。

因此需要一个具有实际物理意义、兼 具等价性, 且能表达灾害对社会经济发展 和人类福祉影响的指标度量灾害影响。Noy 于 2014 年提出灾害影响的生命年 (Disability Adjusted Life Years) 损 失方法 [28], 此种度量可以更好的表达灾 害的影响, 描述实现经济发展和社会进步 所需的时间 [5]。本文使用此方法对汶川地 
震进行案例研究, 计算地震造成的生命年 损失, 并分析灾害影响, 给出对策。

\section{2. 方法和数据}

\section{1 生命年方法}

生命年方法源于世界卫生组织计算疾 病和受伤导致的失能调整生命年损失方法 [29]。最初用于卫生经济学中的成本效果 分析。在风险管理研究中, 研究人员也逐 渐认识到生命长度对于灾害风险管理的意 义, SviatoslavTimashev (2014) 认为健 康的生存长度是人和社会最为宝贵的资 产, 他将平均寿命预期纳入风险管理的研 究中 [30]。Noy（2014）在评估灾害影响时 引入修订的生命年损失的概念, 用以表达 灾害造成的经济发展和社会进步的时间损 失, 将常用的灾害度量指标死亡 (失踪) 人口、受影响人口、经济损失换算为人类 的生命年, 此方法便于对不同地区和国家 的多灾种多事件灾害影响进行比较和趋势 研究, 并利于开展后续成本效益分析研究 [28]。此方法可以避免因单独使用死亡和 经济损失数据而不完全概括受灾程度导致 对灾害结果的过低评价。

使用生命年方法进行灾害影响分析的 应用包括:（1）计算全球或区域灾害造成 的生命年损失及其时间比较: 如计算 19802012 年全球国际报道的灾害共造成超过 13 亿年生命年损失, 同时进行生命年损失的 年比较。（2）计算重大灾害对于单个国家 造成的生命年损失及其区域比较：如泰国 2011 年涺南河洪水导致了 4760 万生命年损 失, 相当于当地居民人均损失 26 天。新西 兰 2011 年 2 月的地震造成 20 万生命年损 失, 平均当地居民人均损失 17 天。（3） 使用生命年进行不同区域和国家的比较, 如计算中低收入国家的灾害生命年损失, 计算发展中小岛国家的灾害生命年损失, 并得到结论灾害引起的 $90 \%$ 以上生命年损失 都分布在中低收入国家, 灾害对社会经济 发展的影响具有不均衡分布。[5] 灾害影响的生命年损失表达式为 [28]:

$$
\begin{aligned}
\text { Lifeyears }= & L\left(M, A_{\text {deat } h}, A_{\text {exp }}\right)+I(N) \\
& +\operatorname{DAM}(Y, P) \\
= & M\left(A_{\text {exp }}-A_{\text {med }}\right)+e T N+ \\
& \frac{(1-c) \delta Y}{P C G D P}
\end{aligned}
$$

其中, $L\left(M, A_{\text {deat } h}, A_{\text {exp }}\right)$ 是死亡（人口）带 来的生命年损失, 根据死亡 (失踪) 人口 数 $(M)$ 、死亡时年龄 $\left(A_{\text {deat } h}\right)$ 和预期寿 命 $\left(A_{\text {exp }}\right)$ 计算。简化后, 使用死亡人群的 年龄中位数 $\left(A_{\text {med }}\right)$ 和 2050 年的人类预期 寿命 $\left(A_{\text {exp }}\right)$ 计算。 $I(N)$ 是受影响人口带来 的生命年损失, 表示受影响人口恢复到受 灾前状态的生命年。应包括严重受伤者的 康复护理成本、在医和后期康复的时间成 本、心理影响、房屋破坏或是生计影响、 暂时和长期的迁移影响, 和其他任何的直 接影响造成的损失。被简化后使用福祉衰 减指数 $(e)$ 、恢复到灾前状态所需时间 $(T)$ 和受影响人口数 $(N)$ 计算。 $\operatorname{DAM}(Y, P)$ 是经济资产损失带来的生命年损 失。表示资产 (或人类劳动成果) 重建的 机会成本。简化后使用直接经济损失 $(Y)$ 、人均 GDP (PCGDP) 计算。使用 $c$ 去掉无关生产的人类活动。 $\delta$ 表示折旧系 数。并采用 $\mathrm{WHO}$ 和 Noy 的研究给常数赋值 ( $A_{\text {exp }}=92, e=0.054, T=3, c=$ $0.75, \delta=2 / 3$ ) [31]。

\section{2 震例介绍}

2008 年 5 月 12 日 14 时 28 分在四川省 阿坝藏族羌族自治州汶川发生 8.0 级地 震, 地震造成 87,150 人遇难, $46,250,000$ 人受灾 $[32]$, 直接经济损失 $85,230,900$ 万 元 [33]。吴昊昱等给出都江堰市的死亡人 口年龄分布, 在此假定地震造成人口死亡 (或失踪) 的年龄分布与此分布相同 [34]。

\section{3. 结果和讨论}

根据公式 (1), 计算得到汶川地震的 生命年损失, 由表 1 所示。汶川地震共造成 $18,359,222$ 年的生命年损失。与常规认知 不同, 生命年损失最大的来源是受影响人 口, 占比 $40.8 \%$; 其次是经济损失; 而死亡 (失踪)人口带来的生命年损失最小, 约 为总生命年损失的 $1 / 4$ 。 
表 1 生命年损失统计表

Table1 Lifeyears losses for Wenchuan Earthquake

\begin{tabular}{ccc}
\hline 生命年损失来源 & $\begin{array}{c}\text { 生命年损失 } \\
\text { (生命年) }\end{array}$ & 比例 \\
\hline L (年) & $4,608,395$ & $25.1 \%$ \\
I (年) & $7,492,500$ & $40.8 \%$ \\
DAM (年) & $6,258,326$ & $34.1 \%$ \\
合计 & $18,359,222$ & $100.0 \%$ \\
\hline
\end{tabular}

就生命年损失来源因素而言, 汶川地震 的最主要生命年损失来源是受地震影响人 口, 其造成的生命年损失远远大于人口死 亡 (失踪) 和经济损失。通常而言, 灾害 发生时最受與论、公众、政府甚至学术界 重视的灾害损失因素是人口死亡（失 踪），但它实际带来的生命年损失却远远 小于受影响人口和资产损失，最不被重视 的灾害影响反而带来最大的灾害生命年损 失。因此应该对灾害后果进行更深刻的理 解, 理解受影响人群代表的隐形的灾害影 响, 并在政策制定时考虑隐形的但却是生 命年损失的灾害后果最主要来源的受影响 人群受到的灾害影响。

从灾害损失中蕴含的时间意义而言, 人 口死亡和失踪代表立时（或短时间）的灾 害反映, 如汶川地震最后救出的幸存者在 瓦砾中坚持了 178 小时 22 分钟, 约为 7.5 天。因此死亡和失踪是以天为计的, 是短 时间范畴的灾害影响; 直接经济损失也更 倾向于较短时间范畴的灾害影响; 而受影 响人群代表的灾害影响, 不论是受伤康 复、还是经济中断的恢复都代表更长时间 范畴的灾害影响。这意味着, 长时间的灾 害影响比短时间的灾害影响更为严重。因 此, 灾害发生之后的应对工作不应仅仅是 短期的应急救援, 应更加重视长期的恢复 和援助。对于灾害影响的评估、监控、援 助的时间限制也应尽量拉长，灾后恢复、 援助和相关政策都应具有足够长的时间长 度, 用以应对灾害影响最重的部分。

\section{4. 结论}

生命年方法可以全面评估灾害损失，可 以更清晰表达灾害对社会经济发展和人类 福祉的影响。

就生命年损失来源而言, 汶川地震的最
主要生命年损失来源是受灾害影响人口代 表的灾害影响, 其造成的生命年损失远远 大于人口死亡 (失踪) 和经济损失。因此 应该对灾害后果进行更深刻的理解, 不仅 仅关注灾后死亡人口。重视受影响人群代 表的隐形的灾害影响, 并在政策制定时考 虑隐形灾害影响。从灾害损失蕴含的时间 意义而言, 受影响人群带来的生命年损失 最大意味着长时间的灾害影响比短时间的 灾害影响更为严重。因此, 应更加重视灾 害发生后的长期恢复和援助, 相关政策应 具有足够时间长度。

\section{Acknowledgements}

This study was supported by The Special Fund of the Institute of Geophysics, China Earthquake Administration (Grant Number DQJB17C10).

\section{致谢}

本研究得到了中国地震局地球物理研究所 基本科研业务费专项的资助（编号: DQJB17C10)

\section{参考文献}

[1] 胡聿贤. 地震工程学 (第二版). 北京: 地震出版社, 2006

[2] 李善邦. 中国地震. 北京:地震出版社, 1981.

[3] UNISDR. Global Assessment Report on Disaster Risk Reduction: Risk and Poverty in a Changing Climate. Geneva, Switzerland: UNISDR, 2009.

[4] UNISDR. GAR Disaster Loss Data Universe, Including a Description of Disaster Datasets, How the Extensive/Intensive Risk Threshold Was Calculated And Other Related Topics. Annex 2 to Global Assessment Report on Disaster Risk Reduction: Risk and Poverty in a Changing Climate. Geneva, Switzerland: UNISDR, 2009.

[5] UNISDR. Global Assessment Report on Disaster Risk Reduction: Making Development Sustainable, The Future of 
Disaster Risk Management. Geneva, Switzerland: UNISDR, 2015.

[6] 马宗晋, 李阂峰. 自然灾害评估、灾度 和对策, 1988 , 中国科学技术协会学 会工作部, 中国减轻自然灾容研究全 国减轻自然灾害研讨会论文集. 北京: 中国科学技术出版社, 1990.

[7] 马宗晋, 杨华庭, 高建国等, 我国自 然灾害的经济特征与社会发展, 科技 导报, 1994. (7): 61-64.

[8] 于庆东, 灾度等级判别方法的局限性 及其改进, 自然灾害学报, 1993, 2(2): $8-11$.

[9] 李祚泳, 邓新民, 使用物元自然灾害 的物元分析灾情评估模型初探, 自然 灾害学报, 1994,3(2): 28-33.

[10] 代博洋, 李志强, 李晓丽, 基于物元 理论的自然灾害损失等级划分方法, 灾害学, 2009, 24( 1): 1-5.

[11] 冯利华, 灾害损失的定量计算, 灾害 学, 1993, 8(2): 17-19.

[12] 赵阿兴, 马宗晋, 自然灾害损失评估 指标体系的研究, 自然灾害学报, 1993, 7(3): 1-7.

[13] 冯志泽, 胡政, 何钧, 地震灾害损失 评估及灾害等级划分, 灾害学, 1994, 9(1): 13-16.

[14] 杨仕升, 自然灾害不同灾情的比较方 法探讨, 灾害学, 1996, 11(4): 35-38.

[15] 任鲁川, 灾害损失定量评估的模糊综 合评判方法, 灾害学, 1996, 1(4): 5-10.

[16] 王蒀, 赵福年, 姚玉璧等, 基于 $Z$ 指 数的石羊河流域干旱特征分析, 灾害 学, 2013, 28(2): 100-106.

[17] 张星, 自然灾害灾情的熵权综合评价 模型, 自然灾害学报, 2009, 18(6): 189-192.

[18] 张鹏, 张云霞, 孙舟等, 综合灾情指 数一一一种自然灾害损失的定量化评 价方法, 灾害学, 2015, 30(4): 74-78.

[19] 汤家法, 王沁, 2013 年北川聚落空间 的地质灾害灾情分析, 灾害学, 2015, 30( 1): 87-91.

[20] 高庆华, 关于建立自然灾害评估系统
的总体构思, 灾害学, 1991, 6(3): 1418.

[21] 王劲峰, 中国自然灾害影响评价方法 研究, 北京: 中国科学技术出版社, 1993.

[22] 魏庆朝, 张庆街, 灾害损失及灾害等 级的确定, 灾害学, 1996, 11(1): 1-5.

[23] 程立海, 唐宏, 周廷刚等, 自然灾害 强度的评估方法及应用一一基于综合 灾情指数的研究, 自然灾害学报, 2011, 20(1): 46-50.

[24] 袁艺, 2000 -2007 年省级区域自然灾害 灾情分析, 自然灾害学报, 2011, 20(1): 156-162.

[25] 廖永丰, 赵飞, 王志强等, 2000-2011 年中国自然灾害灾情空间分布格局分 析, 灾害学, 2013, 28(4): 55-60.

[26] 杜兴信, 窦品玉, 陕西省自然灾害损 失年景和评价指标的研究, 灾害学, 1992, 7(2): 1-6.

[27] 陈秀万, 洪水灾害损失定量指标研 究, 科技通报, 1996, 12(1): 40-42.

[28] NoyIlan. A New Non-Monetary Global Measure of the Direct Impact of Natural Disasters. Background Paper prepared for the 2015 Global Assessment Report on Disaster Risk Reduction. Geneva, Switzerland: UNISDR. 2014.

[29] WHO. WHO Methods and Data Sources for Global Burden of Disease Estimates 2000-2011. Global Health Estimates Technical Paper. Geneva, Switzerland: WHO,

2013.

http://www.who.int/healthinfo/statistics/G lobalDALYmethods_2000_2011.pdf

[30] Sviatoslav T. Average life expectancy as a criterion for regional risk management. Journal of Risk Analysis and Crisis Response, 2014, 4(1): 10-19.

[31] Noyllan. Comparing the Direct Human Impact of Natural Disasters for Two (Surprisingly Similar) Cases: the Christchurch Earthquake and Bangkok Flood in 2011. Background Paper 
prepared for the 2015 Global Assessment Report on Disaster Risk Reduction. Geneva, Switzerland: UNISDR. 2015.

[32] 民政部国家减灾中心, 联合国开发计 划署, 汶川地震救灾救援工作研究报 告, 2009 .

[33] 郑通彦, 李洋, 侯建盛等, 2008 年中
国大陆地震灾害损失述评, 灾害学, 2010, 25(2): 112-118.

[34] 吴吴昱, 间正萃, 董康义等, 都江堰 市汶川地震死亡人数的时空分布研 究, 山西地震, 2011, (4): 40-45. 